\title{
Towards the Standardisation, Officialisation and Promotion of Pidgin English in Cameroon
}

\author{
Charity Besingi Masumbe \\ University of Yaounde 1
}

\begin{abstract}
This paper looks into further developments, functions, attitudes and perceptions of Cameroon Pidgin English (CamP). From the analysis made, it clearly stands out that CamP has become an important linguistic tool with a significant functional load in Cameroon. As such, the researcher stands for its standardization, officialisation and promotion in official domains in general and in the educational sector in particular. CamP must be given the place it deserves in the Cameroonian contexts.
\end{abstract}

DOI: $10.7176 /$ RHSS/10-16-09

Publication date:August $31^{\text {st }} 2020$

\section{Cameroon Pidgin: A historical appraisal, status and functions}

Cameroon is often referred to as Africa in miniature not only with regards to the climate but also with regard to its complex linguistic landscape. In fact, the country is home to two colonial languages: English and French, the official languages par excellence, over 250 indigenous languages (Ethnologue, 2005), and an English-based Pidgin, which is an invaluable language of wider communication across the country. Its origin could be traced as far back as the Slave Trade Years (1400-1800). In fact, the language saw the light of the day out of absolute necessity. It was the linguistic code that served communicative purposes during that period. Though in a complex multilingual setting with its ongoing official neglect by the State, the language has been asserting itself in manifold ways (Tarh: 2007). It has forced its way into areas that were hitherto the preserve of the two official languages (see SimoBobda 2009, Chia 2009). Today, the CamP has a significant functional load in Cameroon. Commenting on the exploits of CamP, Yuka (2001) states that CamP has virtually taken the centre stage, relegating the indigenous languages to the background. The same view is held by Fonlon (1963:402) who argues that CamP was and still is the most widely spoken lingua franca in Cameroon. Chia (1983) re-echoes this claim when he says it is not only widely spoken, but also a very popular language in Cameroon. Mbangwana (2004:23) equally states that $97.8 \%$ of Anglophone and $61.8 \%$ of Francophone Cameroonian urban dwellers speak CamP. Simo Bobda (2009:19) observes that we are gradually moving to a point where Pidgin English, even in university circles, has squatted into domains which were hitherto the preserve of English. He sees English fast becoming a foreign language while Pidgin is commonly used by postgraduate students to discuss Shakespeare and Chomsky, or Nuclear Physics. From the interesting happenings, it is clear that research on CamP is not only complex but perplexing. Chia (2009) thus concludes that the fear here is that since CamP is making in roots into the very fief of Standard English in this nascent role as a language of education discourse, it may eventually supplant Standard English.

It is rather paradoxical that despite the accounts of linguists that show glaringly how CamP has made giant strides towards self-assertion, it is still to attract state attention. Proof of this is the fact that the language is not recognised by the government in any way. In short, CamP does not have any policy statement in respect of the language policy of Cameroon. In the constitution of Cameroon, English and French are recognised as the two official languages. It also takes the engagement to promote and protect the indigenous languages, but no mention is made of CamP.

Despite the pivotal role Cameroon Pidgin plays in the country as a lingua franca, it is still being relegated to the background by the state language policy. It is interesting to note that even the plethora of indigenous languages, which are mutually unintelligible, are being recognised and promoted by the state, CamP is being tagged as the language which is responsible for the falling standards of Education in the country.

\section{Attitudes towards Cameroon Pidgin}

Attitudes towards CamP vary a lot and sometimes they get really confusing especially given that the linguistic landscape is in itself so complex in nature. The main stakeholders such as the English-speaking and the Frenchspeaking Cameroonians, and of course researchers in general exhibit very unpredictable attitudes towards this language. Kelly(1978)pointsoutthatuntilveryrecently,PidginandCreolespeakers have been made to feel ashamed of the language in which they could most easily express themselves. The only thing CamP needs is official recognition by the State because its popularity is growing by the day. Mbufong's (2001) investigation shows that CamP is the first language of most children in the South West and North West regions of Cameroon. He thinks that this is enough for the language to be used for the teaching of children at the initial level of their schooling. This argument is buttressed by the statistics provided by Koenig et al. The table below shows clearly that the 
percentage of children who acquire CamP as their first language outweighs those who acquire Standard English as their first language.

Table 1: Acquisition of English and Pidgin English as First language

\begin{tabular}{|l|c|c|}
\hline Towns & English & Pidgin English \\
\hline Bamenda & $1 \%$ & $22 \%$ \\
Mamfe & $0 \%$ & $25 \%$ \\
Kumba & $1 \%$ & $19 \%$ \\
Buea & $7 \%$ & $26 \%$ \\
Limbe & $4 \%$ & $31 \%$ \\
\hline
\end{tabular}

(Koenig et al. 1983: 98)

More than a decade later, Alobwede (1998: 54) carried out the same survey adding two major cities, Yaounde and Douala, and obtained the following results:

Table 2: The acquisition of English and Pidgin English as first language

\begin{tabular}{|l|c|r|}
\hline Towns & English & Pidgin \\
\hline Bamenda & $3.5 \%$ & $24 \%$ \\
\hline Mamfe & $1 \%$ & $25 \%$ \\
\hline Kumba & $3 \%$ & $22 \%$ \\
\hline Buea & $13 \%$ & $28 \%$ \\
\hline Limbe & $9 \%$ & $30 \%$ \\
\hline Douala & $6 \%$ & $10 \%$ \\
\hline Yaounde & $8 \%$ & $15 \%$ \\
\hline
\end{tabular}

Yaounde

(Alobwede, 1998: 69)

From the above statistics, it is clear that CamP is a growing language that must be taken seriously. Mbufong (2001) wonders why Cameroon policymakers would ignore such a popular language, which is so close to the people, and choose to promoteforeignlanguages.Many Cameroonians tendto identify more withCamP because the language reflects their mother tongues in many ways. There are several thought patterns and lexical elements in CamP, which give it a specific Cameroonian flavour. So, Cameroonians are tempted to transfer that intimacy from their home languages to CamP. They feel at ease discussing in CamP, the same way they would discuss in their mother tongues especially given that the language is non-hierarchical.

Schröder (2003) reports that theattitude of Cameroonians towards CamP at the time of her research was still predominantly negative. Accordingly, the respondents in this study exhibit almost the same attitude as $38 \%$ strongly agree or agree that CamP be taught as a subject in our schools. It should be noted that the attitude of Cameroonians towards the teaching of CamP in our schools is improving by the day. A few decades ago, it was inconceivable to mention the use of CamP in schools, let alone the teaching of the language. I strongly blame the slow pace at which this improvement is going on the indiscriminate banning of the language both in private and public places. But because CamP has developed to a point of no return, it is asserting itself in an admirable way. Recent findings on attitudes towards CamP as a pedagogic language actually show a consistent positive trend despite the enormous intimidation and stigmatisation of its users throughout the country.

In 2001, Kouega carried out an investigation on attitudes towards CamP where, out of 189 informants, 151 respondents $(79.8 \%)$ were against its adoption as a language of instruction in the first three years of education and only 38 respondents $(20.1 \%)$ voted in favour of its institution. Six years later, in 2007, Tarh conducted a similar survey in three towns in Cameroon, namely, the results showed that 53 out of the 142 informants, that is, $37.4 \%$, were willing to have CamP as a pedagogic language in Cameroon. Thus if we follow the trend since 2001 from Kouega's (2001) 20.1\%, through Tarh's (2007) 37.4\% and this study's $38 \%$, even skeptics would not need to be reminded what the future holds for such a self-assertive language as CamP.

\section{Methodological indications}

Research on CamP is very slippery today because the ban placed on the language here and there has sent the eager speakers of the language underground. This has made it very difficult to obtain sincere data from the speakers, especially in respect of their attitudes towards the language. This investigation concentrates on the views of educated Cameroonians because they are better placed to judge which language is appropriate to be used in the education system in a complex multilingual setting such as Cameroon. It is also felt that their views matter more than those of the less educated because they are better placed to influence policies as well as to participate in policy making (Igboanusi: 2008 70). I equally preferred to select respondents from the university community because this linguistic medium is very fashionable among students on campus. Students feel very comfortable discussing even their academic issues in CamP.

In order to defend the case for the valorisation of CamP in Cameroon, we need to back up our argument with scientific evidence. That is why I proceeded to carry out a survey on 100 students from the University of 
YaoundeI. The University of Yaounde I is the mother university in the country and attracts an extensively heterogeneous population from all the ten regions. This is a good breeding ground for CamP, which the students prefer because it is very flexible, fashionable and a language of intimacy. A thirteen-item questionnaire with evaluatively-worded statements was designed and distributed to the students with a 4-Likert scale (marking agreement or disagreement) following (Hyland, 1997; Lasagabaster:2003; Lai,2005). The results of the questionnaire are analysed and discussed below.

\section{Presentation, interpretation and discussion of the main findings}

One of the key issues of this research endeavour was to critically examine the different attitudes towards CamP in education-related issues and the informants' perception of this linguistic medium. The table below synthesizes those attitudes and perceptions

Table 3: Attitudes toward CamP

\begin{tabular}{|c|c|c|c|c|}
\hline Opinions & $\begin{array}{l}\text { Strongly } \\
\text { agree }\end{array}$ & Agree & $\begin{array}{l}\text { Strongly } \\
\text { disagree }\end{array}$ & Disagree \\
\hline $\begin{array}{l}\text { 1.Cameroon Pidgin influences your English in a very negative } \\
\text { way }\end{array}$ & $30 \%)$ & $30 \%$ & $25 \%$ & $15 \%$ \\
\hline 2. Pidgin should be spoken on campus & $20 \%$ & $25 \%$ & $32 \%$ & $23 \%$ \\
\hline 3. Pidgin is the preserve ofuneducated people & $15 \%$ & $15 \%$ & $30 \%$ & $40 \%$ \\
\hline 4. Pidgin should be taught as a subject in schools & $18 \%$ & $22 \%$ & $35 \%$ & $25 \%$ \\
\hline 5. Pidgin should be used as amedium of instruction in schools & $11 \%$ & $20 \%$ & $42 \%$ & $27 \%$ \\
\hline $\begin{array}{l}\text { 6. Pidgin should be made one of the official languages in } \\
\text { Cameroon }\end{array}$ & $21 \%$ & $28 \%$ & $33 \%$ & $18 \%$ \\
\hline 7. Pidgin is a language of intimacy & $44 \%$ & $45 \%$ & $08 \%$ & $03 \%$ \\
\hline 8. Pidgin is easy to learn & $19 \%$ & $10 \%$ & $30 \%$ & $41 \%$ \\
\hline 9. Pidgin is easy to speak but difficult to write & $28 \%$ & $40 \%$ & $18 \%$ & $14 \%$ \\
\hline 10. Pidgin is an important lingua franca in Cameroon & $39 \%$ & $46 \%$ & $09 \%$ & $10 \%$ \\
\hline 11. Pidgin does not discriminate its speakers & $45 \%$ & $46 \%$ & $00 \%$ & $09 \%$ \\
\hline 12. Pidgin is just like one of our indigenous languages & $33 \%$ & $38 \%$ & $10 \%$ & $19 \%$ \\
\hline 13. For Pidgin to be taught in schools, it needs to be codified & $30 \%$ & $43 \%$ & $10 \%$ & $17 \%$ \\
\hline
\end{tabular}

The analysis shows markedly that CamP is a very prominent language in Cameroon. The respondents in this study confirm this. As many as 39\% strongly agree and $46 \%$ agree that it is an important lingua franca, against $15 \%$ who strongly disagree. In fact, Atechi and Fonka (2007) show that CamP is not only a lingua franca in the English-speaking part of the country but also in most French-speaking settings. The language has spread its roots to all the regions of the country, assuming many functions and statuses.

Again, CamP is a language of intimacy. Once out of office, most Cameroonians interact with each other using CamP. During political campaigns, CamP is usually used in addressing the masses. Politicians use this language to bridge the gap that English and French have created between them and the masses. It gives the impression that the politicians are close to the people. It is the language of the people, be they from the North, South, East, West, be they illiterate or literate, French-speaking or English-speaking. The findings in this paper confirm this very clearly as $44 \%$ of the respondents strongly agree and $45 \%$ agree to the statement that CamP is a language of intimacy.

For CamP to gain more recognition and legitimacy, it needs to be promoted to a medium of instruction in schools. Researchers such as Alobwede (1998), Mbangwana (1983, 2004), or Mbufong (2001), suggest it should be used in school. They base the thrust of their arguments on the functions and statuses the language assumes throughout the country.

Regarding the suggestion that CamP be made an official language, $49 \%$ of the respondents either strongly agree or agree, while $51 \%$ strongly disagree or agree. It means that the covert prestige enjoyed by CamP lies in the fact that the State does not care about this linguistic medium? Hall (1972151) intimates that the lone factor liable to change the status of a Pidgin is a political one. Schröder $(2003: 248)$ thinks that most Cameroonians are not particularly open to- wards the introduction of CamP as a means of instruction, not because of its supposedly detrimental influence on Standard English acquisition or on the educational standards as a whole, but because of its language developmentstatus.

\section{Codifying Cameroon Pidgin English: an urgent need}

While the majority of the respondents $(81 \%)$ disagree with the statement that CamP is easy to learn, they did agree $(68 \%)$ that CamP is easy to speak but difficult to write. There is a general consensus on the difficulties of writing CamP and the need for the language to be codified. The respondents $(70 \%)$ strongly agree or agree with the statement that, for CamP to be taught in schools there is dire need for codification. It may be useful to remark 
that the question of codification is a very serious one if the language must be taught in schools. For any language to be taught, it must have a standard orthography, which will, in turn, spur the creation of dictionaries and grammar books on the language. CamP has no officially sanctioned orthography even though it is undoubtedly the most spoken language in Cameroon.

Sala (2009 11) reechoes the concern that CPE writing is marred by inconsistencies. He thinksthat the writing system for CamP should follow the English orthography as much as we lose nothing, and deviate from it as much as we gain something. From this conclusion, it is very clear that dust is still to settle on this matter. The earlier there is a consensus on this matter, the better; given that studies on more advanced aspects of CamP have been and are being carried out with foundational issues like the writing system still pending. This may just be like putting the cart before the horse. Codification and eventual standardization of CPE, Mbangwana thinks, will enable the language to enjoy stability, reasonable uniformity, autonomy and authority (2004:39).

We follow that it is possible for low-status languages to be promoted to the extent that they can be used in prestigious domains hitherto the preserve of official languages (Igboanusi: 2008). A glaring case in point is Kiswahili in East Africa as cited by Simala, Kembo-Sure and Ogechi (2006). This implies that a language's role is strongly determined by factors like empowerment or marginalisation, and that any language can be empowered if matters of status and corpus planning are addressed. CamP badly needs this therapy so as to enjoy overt prestige like French and English in Cameroon. This type of empowerment will only be a step in the right direction given that Pidgins and Creoles are already enjoying a new status in some parts of the world. Simo Bobda (2006:75) reports that Kriolu is the national language in the Cape Verde Islands, while Creole is now coofficial with French in Haiti. This kind of recognition makes Creole a language of education in Haiti (Igboanusi, 2008:75). In Sierra Leone, Krio is enjoying the status of a national language, alongside Limba, Membe, and Temne, and has been standardized (Sandred 1996). Sandred (1996) further reports that Krio is now being used in primary education, in adult literacy campaigns, in newspaper articles and for serious creative literature. CamP is already being extensively used in the media. What we need to do is to further empower this language of wider communication and intimacy so that it can be fully useful to its users as it were.

\section{Challenges facing the valorization of CamP}

The challenges facing the valorization of CamP are many. First, the fact that it is perceived to be a poor version of Standard English can militate against its acquisition, not unlike the thinking that if we do away with Pidgin English, children's performance in English would improve. The amusing thing about this type of wishful thinking is that people fail to understand that the relationship between Pidgin English and English is too complex to suggest that simply eradicating Pidgin will be a magic solution to the problems children face in English.

Second, hypocrisy is one of the major challengesCamP is facing in Cameroon. Cameroonians of all walks of lifeuse CamP in varied ways in their day-to-day functioning in society. Students use it in class to discuss with friends and sometimes with their teachers (see Chia: 2009; Simo Bobda: 2009), parents use it with friends at home, in their offices, etc.; teachers use the language with students on campus, in the streets and even in some official settings. Both educated and uneducated persons use the language. In fact, it is just like the air they breathe. However, the same people, who make extensive use of this language, tend to exhibit a rather negative attitude towards it when it comes to declaring their attitudes overtly. As earlier stated, I blame this on the massive intimidation and stigmatisation that are going on in the country in varied forms. Simo Bobda (2009:19) thinks that this stigmatisation and intimidation is due to the fact that the status of Pidgin English has significantly improved of late. He points out that it is because Pidgin English is threatening the hegemony of English even in university circles, that university authorities are forced to devise means to eradicate it. A case in point is the University of Buea, where the authorities have erected signboards with the following inscriptions to reinforce the ban on this idiom oncampus:

No Pidgin on Campus please!

Pidgin is taking a heavy toll on your English; shun it. The medium of studies at UB is

English, not Pidgin If you speak Pidgin, you will writePidgin.

English is the password, not Pidgin Speak less Pidgin and more English

Inscriptions of this nature are conspicuous in many public and private higher institutions, while other private and government-owned schools have outrightly banned its use on the school premises. These and many more have in large measure contributed to the attitudes towards CamP today. Thus when researchers go out for surveys on CamP, it is always very difficult to get results that paint a vivid picture of the situation on the ground. This type of intimidating scenario for users of CamP witnessed in Cameroon is not an isolated case. The same shabby treatment of Pidgin English speakers is equally reported in Nigeria and Ghana. In Ghana, for example, Huber (2008: 95) reports that schools strongly discourage the use of Pidgin, but boys freely resort to it when unobserved by teachers. He asserts that Pidgin English in Ghana serves as a social register, as an in-group language, being used not so much out of the communicative necessity but as a means of expressing solidarity and intimacy with peers. Pidgin has established itself in the university as the main informal code of male 
students. It is heard on campus, in students bars, and in the halls of residence (Huber: 2008 96).

It should also be pointed out that gone are the days when CamP was used out of communicative necessity. It can safely be asserted that the language has gradually established itself in the linguistic landscape of Cameroon, assuming many functions and statuses. It is almost unthinkable that it can be supplanted by another language, may be just because it is backed by the language policy of the country. By implication, the evolution observed in CamP is simply moving the language to a point where it will stabilize and establish itself as a more solid force to reckon with in the country's complex linguistic make-up and thus should be given a chance in prestigious domains.

The uncomfortable atmosphere created around the speaker of CamP has made respondents suspicious. This has caused them to become hypocrites each time you approach them for any inquiry on the language. Researchers are therefore expected to devise other means to collect data on CamP. This is why I must salute the approach used by Chia (2009) to investigate the use of CamP in the University of Buea. Regarding the difficulties involved in collecting authentic data from the students, he remarks, - we were aware that if we asked students simply to indicate whether or not they spoke CamP, the answer would be overwhelmingly negative even in answering anonymous questionnaires, because of the ban. The results obtained by Chia (ibid), $63 \%$ for CamP, $25 \%$ for English and $11 \%$ for French paint a vivid picture of the popularity of CamP. This study goes a long way to complement Chia's findings as it opts for the open method of eliciting attitudes. These results put side by side reveal how sensitive the process of measuring attitudes towards CamP can be. It is marred by hypocrisy and suspicion because of the tension created here and there by government and some individuals who see CamP in the bad light.

\section{The way forward}

From all indications, CamP has elbowed its way and established itself as a dominant language in the linguistic land- scape of Cameroon, despite the reluctance by government to give it an official place in the language policy of the country. For CamP to enjoy overt prestige and probably find itself in more prestigious domains such as the classroom, a number of measures need to be taken.

First, governmental authorities should duly recognize it, that is, give it a place in its constitution or in its language policy, as it is the case with the two official languages and the indigenous languages. The revision of the language policy to cater for the concerns raised in this paper will leave a serious impact on the attitudes of Cameroonians towards CamP. It should not only be recognized but should also be promoted and protected in domains, such as education, that will give the language the prestige it deserves. Schneider (2005) asserts that education is the most important institution through which we can implement language policies. CamP should be given a chance in the education system by being used as a medium of instruction in early primary education and at least taught as a subject in both secondary and tertiary levels. This step, it is hoped, will positively affect the status of the language as attitudes towards the language would change through encouragement fromteachers.

Second, education officials should organise language awareness seminars, classes or in-services for teachers, which include strategies for building on the home language and for understanding language systems, as well as language awareness programs for students to learn about the history and social functions of both Pidgin and English, and to discover ways in which Pidgin and English are different. Research on the relationship between Pidgin and school success, and how to best build on the language that children come to school with in the achievement of school success should be thoroughly conducted. A basic and well-established educational principle is to build on the strengths that children come to school with. Local children tend to have linguistic strengths which include exposure to and knowledge of a variety of languages and abilities to move between language varieties for various purposes. Building on these strengths would entail discussing language and language variation as part of the schoolcurriculum.

On the other hand, telling children that the way they speak is bad, incorrect or inappropriate often leads to one of the following consequences: children withdraw and choose not to speak and participate in class rather than risk saying something "wrong" they develop negative academic self-concepts labeling themselves as "bad students" and behave accordingly; language becomes an issue and a site of struggle between students and teachers, creating a counter-productive educational atmosphere. Since language is such a central part of identity, to attack someone's language is to attackthem.

Third, the challenges of orthography and eventual codification of CamP echoed and reechoed by many (Hall: 1972; Schröder: 2003; Mbangwana: 2004; Atechi \& Fonka: 2007; Sala:2009) should be taken very seriously if CamP must gain overt prestige. A lot has already been written in CamP, such as the New Testament Bible by the Cameroon Bible Society,Some Day Bin Day, by Todd, and the CamP Dictionary by Kouega, and so on. The introduction of a codified CamP as a medium of instruction is a first step towards its general recognition and eventual acceptance as a language of national integration. Government should do well to give incentives to those who write in CamP, encourage the design of syllabuses of CamP as well as didactic materials for the successful learning and teaching of the language. 
The teaching of CamP will uplift the ban on its use in schools and other public and private places, thereby making way for many people to have access to it. This will foster unity, as it will no longer be termed a broken form of English used by Anglophones, but seen as a tool to bring Cameroonians of all walks of life on board a single ship of state. This can only be a good thing for a country whose multilingual setting, instead of helping to, tends to destroy its unity.

Finally, the myth according to which "if we could do away with Pidgin, our children's writing scores would go up" is not founded on any empirical evidence. The reality is that the relationship between Pidgin and English is too complex to suggest that simply eradicating Pidgin will raise scores. Very little research has been conducted to understand the relationships between Pidgin and English. To implicate Pidgin as the cause of children's poor Standard English writing skills is academically unjust and scholastically irresponsible. We should recognize that Pidgin is the first language of many children in Cameroon and that the process of comparing Pidgin to English and other languages will be an extremely effective means of developing the understanding of variations in world languages and preparing students for the acquisition of additional languages.

If these suggestions are taken seriously, this will obviously change the attitudes of Cameroonians towards CamP. Parents will now allow their children to speak their most cherished language freely; students will now feel more at ease to speak this language with their teachers and among themselves, without being afraid of punishment. The valorization of CamP will clearly distinguish it from Standard English and thus reduce the fear of both parents and teachers that using CamP will have an adverse effect on their performance in English Language.

\section{References}

Adegbija, Efurosibina. Language Attitudes in Sub-Saharan Africa: A So- ciolinguistic Overview. Clevedon: Multilingual Matters, 1994.

Atechi, Samuel. "The Phonological influence of English on Awing”. EnglishStudies Vol. 87, 2006, 230-47.

AtechiSamuel. \&HansFonka. "Pidgin Englishas a Lingua Franca in Cameroon".PEL. Vol. 4, 2007,28-39.

AlobwedeD‘Epie. “Banning Pidgin English in Cameroon?”English Today, 14(1), 1998, 54-60.

Chia, Emmanuel. "Cameroon home languages".inKofele, Kale (ed.) AnAfrican Experience in Nation Building: the Bilingual Cameroon Repub- lic since Reunification, Boulder, Co: West View, 1983, 281-311.

.Further Developmentsin Cameroon Pidgin English",in Annals of the Faculty of Arts, Letters and Social Sciences. Special Edition in Honour of Professor Paul N. Mbangwana, 2009,39-50.

Chiatoh, Blasius. "Language, Cultural Identity and the National Question in Cameroon", in Mbangwana, Paul, Kizitus Mpoche \& Tennu Mbuh eds). Language, Literature \& Identity. Gottingen: Cuvillier Verlag, 2006, 44-52.

Coulmas, F. Sociolinguistics: The Study of Speaker's Choice. Cambridge: Cambridge University Press, 2005.

Deuber, Dagmar. Nigerian Pidgin in Lagos: Language Contact, Variation and Change in an African Urban Setting. London: Battlebridge, 2005.

Fonlon, Bernard. Review article on Some Day Be Dey, by Loreto Todd.

ABBIA, 1963, 31-33.

Haugen, Einar. "Linguistics and Language Planning", in W. Bright (ed.). Sociolinguistics Proceedings of the UCLA Sociolinguistics Conference, The Hague: Mouton, 1964, 50-71.

Huber, Magnus. "Ghanaian Pidgin English: Phonology", in Rajend Mes-thrie (ed.) Varieties of English, Africa, South and South-East Asia. Berlin; New York: Mouton de Gruyter, 2008, 93-101.

Hyland, K.““'Language Attitudes at the Handover: Communication and Identity in 1997 Hong Kong”.English Worldwide, 18, 1997, 191-210.

Igboanusi,Herbert.“EmpoweringNigerianPidgin:AChallengeforStatus Planning?”.World Englishes, Vol. 27, No. $1,2008,68-82$.

Kelly, Michael. "Taking Pidgin Seriously". ABBIA, (31-33), 1978, 285-96.Koenig, Edna, Emmanuel Chia, \&Povey, John (eds.) A Sociolinguistic Profile of Urban Centres in Cameroon, Los Angeles: Crossroads, Univ.of California, 1983.

Kembo-Sure \& Ogechi, Nathan O. "Language Planning and Reform: An Alternative Language Policy for Kenya", in Kembo-Sure, Sera Mwangi, \& Nathan O. Ogechi. Eldoret (eds.) Language Planning for Development in Africa. Moi University Press, 2006, 37-53.

Kouega, Jean-Paul. "Pidgin Facing Death in Cameroon". Terralingua Discussion Paper No17, 2001. www.terralingua.org/Discussion pa- pers.html: 20/07/2008.

Lai, Mee-Ling. "Language Attitudes of the First Post-colonial Generation in Hong Kong Secondary Schools". Language in Society, 34, 2005, 363-88.

Lasagabaster, David. "Attitudes towardsEnglish in the Basque Autono- mous Community". World Englishes, 22(4), 2003,585-97.

Mbangwana, Paul. "The Scope and Role of Pidgin English in Cameroon”,in Edna, Koenig et al. (eds.) The 
Sociolinguistic Profile of Urban Centres in Cameroon. Los Angeles: Crossroads Press, 1983, 79-92.

. "Pidgin English in Cameroon: A Veritable Linguistic Menu", in Echu, George \& Obeng, S. (eds.) Africa Meets Europe: Language Contact in West Africa. New York: Nova Science Publishers, 2004, 23-44.

Mbufong,P.K."Pidgin English in Anglophone Education,English Today, 17(3), 2001, 52-54.

Nanfah, Gaston."Exoglossic Language Policy and National Unity in Africa: The Cameroonian Model", in MbangwanaP., Kizitus Mpoche \& Mathias Mbuh (eds.) Language, Literature and Identity. Göttingen: CuvillierVerlag, 2006, 129-43.

Sala Bonaventure. "Aspects of the Cameroon English Sentence", un-published PhD thesis, University of Yaounde I, 2003.

. "Writing in Cameroon Pidgin English: Begging the Question", in English Today 98, vol. 2, June 2009, $11-17$.

Sala B. \& A. Ngefac. "The Depidginisation Process in Cameroon Pidgin English”, in PhiN, No 36, 2006.

Sandred, Karl Inge. "A West Africa Creole Language in an Atlantic Perspective: The Origins and Present State of Krio", in Sture Ureland \& Iain Clarkson (eds.). Language Contact Across the North Atlantic, Tubingen: Niemeyer, 1996, 528-42

Schneider, Britta. Linguistic Human Rights and Migrant Languages.

Frankfurt am Main: Peter Lang, 2005.

Schröder, Anne. Status, Functions, and Prospects of Pidgin English: An Empirical Approach to Language Dynamics in Cameroon. Tubingen: Narr, 2003.

Simala, Inyani. "Kiswahili inEast African Community Education: Chal- lenges and Opportunities", in KemboSure, Sera Mwangi\& Nathan Ogechi. Eldoret (eds.). Language Planning for Development in Africa. Moi University Press, 2006, 97-110.

SimoBobda, Augustin. "Facing some Challenges in Language Planning for Cameroon", in Kembo-Sure, Sera Mwangi, Nathan Ogechi, Eldoret (eds.). Language Planning for Development in Africa. Moi University Press, 2006, 71-86.

."The Heritage of Professor Paul Nkad Mbangwana", Keynote Paper, in Annals of the Faculty of Arts, Letters and Social Sciences. Special Edition in Honour of Professor Paul N. Mbangwana, 2009, 17-25.

Tadadjeu, Maurice."Prospects for Language Planning Studies in Cameroon", in Koenig et al. (eds.). $A$ Sociolinguistic Profile of Urban Centers in Cameroon. Los Angeles: Crossroads Press, 1983, 117-24.

Tarh, Immaculate. "Pidgin English as a Self Assertive Language in Cameroon", unpublished M.A dissertation, University of Yaounde I, 2007.

Tod, Loreto. "English in Cameroon: Education in a Multilingual Society", in Pride, John (ed.) New Englishes, Rowley MA: Newbury House, 1982, 119-37.

Yuka, Constantine. "On English as a Minority Official Language", Language Attitude and Language Conflict in WestAfrica. Ibadan: Enierownfit Pub. 2001, 143-51. 